\title{
Metal-Free Fabrication of Fused Silica Extended Nanofluidic Channel to Remove Artifacts in Chemical Analysis
}

\author{
Kyojiro Morikawa ${ }^{1, *(D)}$, Ryoichi Ohta ${ }^{1}$, Kazuma Mawatari ${ }^{2, *}$ and Takehiko Kitamori ${ }^{1,3}$ \\ 1 Collaborative Research Organization for Micro and Nano Multifunctional Devices (NMfD), \\ The University of Tokyo, 7-3-1 Hongo, Bunkyo, Tokyo 113-8656, Japan; ohta@icl.t.u-tokyo.ac.jp (R.O.); \\ kitamori@icl.t.u-tokyo.ac.jp (T.K.) \\ 2 Department of Applied Chemistry, School of Engineering, The University of Tokyo, 7-3-1 Hongo, Bunkyo, \\ Tokyo 113-8656, Japan \\ 3 Institute of Nanoengineering and Microsystems (iNEMS), Department of Power Mechanical Engineering, \\ National Tsing Hua University, No. 101, Section 2, Kuang-Fu Road, Hsinchu 30013, Taiwan \\ * Correspondence: morikawa@icl.t.u-tokyo.ac.jp (K.M.); kmawatari@g.ecc.u-tokyo.ac.jp (K.M.)
}

Citation: Morikawa, K.; Ohta, R.; Mawatari, K.; Kitamori, T. Metal-Free Fabrication of Fused Silica Extended Nanofluidic Channel to Remove Artifacts in Chemical Analysis. Micromachines 2021, 12, 917. https:// doi.org/10.3390/mi12080917

Academic Editor: Takasi Nisisako

Received: 29 June 2021

Accepted: 30 July 2021

Published: 31 July 2021

Publisher's Note: MDPI stays neutral with regard to jurisdictional claims in published maps and institutional affiliations.

Copyright: (c) 2021 by the authors. Licensee MDPI, Basel, Switzerland. This article is an open access article distributed under the terms and conditions of the Creative Commons Attribution (CC BY) license (https:// creativecommons.org/licenses/by/ $4.0 /)$.

\begin{abstract}
In microfluidics, especially in nanofluidics, nanochannels with functionalized surfaces have recently attracted attention for use as a new tool for the investigation of chemical reaction fields. Molecules handled in the reaction field can reach the single-molecule level due to the small size of the nanochannel. In such surroundings, contamination of the channel surface should be removed at the single-molecule level. In this study, it was assumed that metal materials could contaminate the nanochannels during the fabrication processes; therefore, we aimed to develop metal-free fabrication processes. Fused silica channels 1000 nm-deep were conventionally fabricated using a chromium mask. Instead of chromium, electron beam resists more than $1000 \mathrm{~nm}$ thick were used and the lithography conditions were optimized. From the results of optimization, channels with $1000 \mathrm{~nm}$ scale width and depth were fabricated on fused silica substrates without the use of a chromium mask. In nanofluidic experiments, an oxidation reaction was observed in a device fabricated by conventional fabrication processes using a chromium mask. It was found that $\mathrm{Cr}^{6+}$ remained on the channel surfaces and reacted with chemicals in the liquid phase in the extended nanochannels; this effect occurred at least to the micromolar level. In contrast, the device fabricated with metal-free processes was free of artifacts induced by the presence of chromium. The developed fabrication processes and results of this study will be a significant contribution to the fundamental technologies employed in the fields of microfluidics and nanofluidics.
\end{abstract}

Keywords: microfluidics; nanofluidics; extended nanochannel; nanofabrication; fused silica; metal-free

\section{Introduction}

Miniaturized analytical systems known as microfluidics, micro-total analysis systems ( $\mu$-TAS), and lab-on-a-chip have attracted much attention over the past 30 years $[1,2]$. In this concept, microfluidic channels are fabricated on a substrate and various types of chemical and biochemical processes are integrated into the channels. When compared with bulk processes, there are many advantages with such miniaturized analytical systems, such as ease of analysis, high-speed reaction, low reagent consumption, and small sample volumes. One of the most significant characteristics of these analytical systems is the temporal-spatial uniformity. Considering their typical diffusion time, molecules diffuse over micrometer regions within the order of seconds. Therefore, molecular transport in liquids, even at liquid/liquid interfaces, gas/liquid interfaces, and solid/liquid interfaces, can be completed within a very short time. In addition, considering the small heat capacity of liquids inside a microfluidic channel, the temperature can be instantaneously changed. Such characteristics are essential for the control of chemical reactions, and are not observed in bulk-scale chemical reactions; therefore, microfluidic devices have received 
much attention as chemical reaction tools. Polymers [3-9] such as polydimethylsiloxane (PDMS) and polymethyl methacrylate (PMMA), and paper [6,7,10-13] are widely used as materials for microfluidic devices, mainly for biochemical and bioanalytical devices. The main advantages of these materials include their ease of fabrication and their low cost. On the other hand, glass [9,13-15], which has high purity, high chemical and mechanical stability, high optical transparency, and allows facile surface modification, has proven to be a suitable material for chemical and biochemical microfluidic devices. Glass tools such as beakers, pipettes, etc., have been widely used for chemical experiments on the bulk scale, so that there is increasing interest in glass microfluidic devices for chemical experiments in microfluidics.

Since the 2000s, the field of nanofluidics has advanced with downscaling of microfluidics [16-20]. Compared to microspaces, size confinement effects are much more enhanced in nanospaces. A typical volume in a nanospace is from picoliters $\left(\mathrm{pl}, 10^{-12} \mathrm{~L}\right)$ to femtoliters ( $\mathrm{fl}, 10^{-15} \mathrm{~L}$ ), and the number of molecules in the spaces is at the single-molecule level $(\mathrm{nM} \times \mathrm{fl}=1$ molecule). In addition, the surface to volume ratio in nanospaces reaches $10^{-8}-10^{-7} \mathrm{~m}^{-1}$, i.e., molecules in the liquid phase can easily and quickly contact nanochannel surfaces without the use of a mixer. Novel devices for reactions at solid (nanochannel surfaces)/liquid interfaces have been developed using this principle. For example, the biotin-streptavidin reaction [21,22], hybridization of microRNA [23], enzymatic reactions [24], and electrochemical reactions $[25,26]$ have been performed at solid/liquid interfaces in nanochannels. In our group, a picoliter enzymatic reactor [27] using an enzyme-immobilized nanochannel, and femtoliter chromatography devices $[28,29]$ using silica surfaces or $\mathrm{C}_{18}$-modified surfaces have been developed, and their superior performance over conventional bulk methods has been verified. A femtoliter enzyme-linked immunosorbent assay (ELISA) [30] using antibody-immobilized nanochannels enabled protein quantification at the single-molecule level. In addition, integration methodologies known as micro unit operations (MUOs), nano unit operations (NUOs), and continuous flow chemical processing (CFCP) [31] have been used to realize devices for living single-cell analysis [32]. Therefore, nanochannels with functionalized surfaces can act as a reaction field, and thus nanofluidics has received much attention as a chemical reaction tool.

However, a countermeasure to contamination is essential in the use of nanochannels, and this should be performed at the single-molecule level because molecules in nanochannels are handled at this level. Contamination during nanochannel fabrication processes is no exception. Electron beam (EB) lithography, photolithography, and dry etching are the main processes we employ for the fabrication of fused silica nanochannels/microchannels [33]. In these processes, different etching masks are used based on the target channel dimensions. To select the etching masks, mainly two factors should be considered: lithography resolution and etching resistivity. For example, an EB resist can be used to perform lithography with $100 \mathrm{~nm}$ scale resolution, but channel depth will be less than $100 \mathrm{~nm}$ scale after etching due to etching selectivity of the EB resist/fused silica. A photoresist can be used to perform lithography with $1 \mu \mathrm{m}$ scale resolution, but channel depth will be less than $1 \mu \mathrm{m}$ scale after etching due to etching selectivity of the photoresist/fused silica. To improve etching resistance while keeping the lithography resolution, a combination of EB resist and metal mask or combination of photoresist and metal mask are widely used. In our group, combination of EB resist and metal mask (mainly chromium) are used to fabricate channels where the width and depth are 500-5000 nm (which is called extended nanochannels [19]), and combination of photoresist [34] and chromium are mainly used to fabricate microchannels where the width and depth are 5-50 $\mu \mathrm{m}$. Chromium contributes very well to these fabrication process, as well as conventional fabrication methods. However, if chromium or its oxidation products remain on extended nanochannel surfaces, they have a negative effect on chemical reactions in the extended nanochannel because they are active for redox reactions. The reaction derived from chromium can disturb target chemical reaction in the extended nanochannel; artifacts from chromium reaction can be induced. For example, TMB $\left(3,3^{\prime}, 5,5^{\prime}\right.$-tetramethylbenzidine) 
is widely used as a substrate in enzymatic amplification reaction for protein analyses such as ELISA, Western blotting, etc. Redox reactions between chromium and TMB can disturb target enzymatic reaction of TMB; as a result, detection of signals from a target enzymatic reaction will be difficult. Therefore, chromium-free fabrication methods are desirable to avoid this problem. A photoresist can be used instead of chromium masks for microchannel fabrication; however, it is difficult to find an alternative to chromium for the fabrication of extended nanochannels. One typical approach to the fabrication of extended nanochannels without chromium is the use of a thicker EB resist (the thickness of a conventional resist is less than $1000 \mathrm{~nm}$ [35]). However, considering the lithography principle, the formation of narrower lines is difficult with a thicker resist. There is little information on the use of thick resists because the research trend is mainly aimed at the fabrication of narrower nanochannels using thinner resists, as typified by the fabrication of semiconductor silicon [36,37]. In addition, fused silica has higher etching resistivity than silicon; therefore, a thicker resist would be required for the fabrication of fused silica extended nanochannels, which indicates more difficult fabrication.

In this study, a process for the fabrication of fused silica channels with widths and depths on the scale of $1000 \mathrm{~nm}$ is presented. To realize this process, an EB resist with a thickness of approximately $2000 \mathrm{~nm}$ was coated on fused silica. The EB exposure time was optimized for the thick resist, and the channel dimensions after etching were evaluated. Finally, artifact removal from analyses was evaluated. As a model sample, TMB was used, and devices fabricated by conventional chromium mask processes and those fabricated by the metal-free process developed were used in this study.

\section{Materials and Methods}

Figure 1 shows the various fabrication processes for the nanofluidic devices. First, an EB resist (ZEP-520A, Zeon Corp., Tokyo, Japan) was spin-coated onto a fused silica substrate (VIO-SILSX, Shin-Etsu Quartz Co., Ltd., Tokyo, Japan; $70 \times 30 \times 0.7 \mathrm{~mm}$ ). After spin-coating, the substrate was heated at $180^{\circ} \mathrm{C}$ for $2 \mathrm{~min}$. The substrate was then spincoated again using the same spin speed. After the second spin-coating, the substrate was again heated at $180^{\circ} \mathrm{C}$ for $2 \mathrm{~min}$. In these processes, three types of substrates were prepared with different spin-coating speeds of 500, 700, and $1000 \mathrm{r} / \mathrm{min}$. EB lithography was subsequently performed. The exposure area was designed as lines and spaces, where the width of the lines was 1000, 1500, 2000, 2500, 3000, 3500, and $4000 \mathrm{~nm}$ with various exposure times $(0.2,0.3,0.4,0.5,0.6,0.7,0.8,0.9$, or $1.0 \mu \mathrm{s} / \mathrm{dot} ; 1$ dot $=5 \times 5 \mathrm{~nm}$ area). After EB lithography, development was performed by dipping in $o$-xylene, and the thickness of the EB resist was then measured. Dry etching was then performed using an NLD-570 system (Ulvac Co., Ltd., Kanagawa, Japan) with gaseous $\mathrm{SF}_{6}$ and $\mathrm{CHF}_{3}$. The etching time for the substrate coated twice at $500 \mathrm{r} / \mathrm{min}$ was $1200 \mathrm{~s}$, that coated twice at $700 \mathrm{r} / \mathrm{min}$ was $1000 \mathrm{~s}$, and that coated twice at $1000 \mathrm{r} / \mathrm{min}$ was $800 \mathrm{~s}$. The etching profiles of the channels were measured with a stylus profiler (dektakXT-A, Bruker Corp., Billerica, MA, USA) and an optical profiler (WYKO NT9100A, Bruker Corp., Billerica, MA, USA).

Microchannels for liquid introduction with a width of $500 \mu \mathrm{m}$ and a depth of $2 \mu \mathrm{m}$ were fabricated on another substrate. Two different devices were prepared for verification of artifact removal. The processes for fabrication of these two devices were based on flELISA devices [30]. In device 1, microchannels were fabricated using a chromium mask and a photoresist material (OFPR-800, Tokyo Ohka Kogyo Co., Ltd., Tokyo, Japan). In these processes, photolithography was performed on the substrate coated OFPR-800 photoresist and chromium. After the development of an OFPR- 800 photoresist with dipping in tetramethylammonium hydroxide (TMAH) solution, chromium was etched by dipping in a chromium etchant solution $\left(\mathrm{Ce}\left(\mathrm{NH}_{4}\right)_{2}\left(\mathrm{NO}_{3}\right)_{6}\right)$. In device 2, THB type (no metal) photoresist (JSR Corp. Tokyo, Japan) [38] was used to fabricate microchannels for comparison with the effects of chromium. Photolithography was performed on the substrate coated THB type photoresist, and after that, development was performed by dipping in TMAH solution. The difference between devices 1 and 2 was the different microchannel fabrication process with/without 
chromium. After that process, the substrates of both devices 1 and 2 were patterned with amino-propyltriethoxysilane (APTES). Each type of substrate with microchannels was bonded to another substrate with extended nanochannels by a low-temperature bonding method [39]. The extended nanochannels for devices 1 and 2 were fabricated by the following method: twice coating at $1000 \mathrm{r} / \mathrm{min}, 2000 \mathrm{~nm}$ exposure area, $0.6 \mu \mathrm{s} /$ dot exposure time, and dry etching with $720 \mathrm{~s}$. Prior to this bonding process, fluorine was added during plasma treatment of the extended nanochannel fabricated substrates. Vacuum ultraviolet (VUV) treatment was performed for the microchannel fabricated substrates. After bonding, the channel surfaces were modified with polyethylene glycol (PEG).

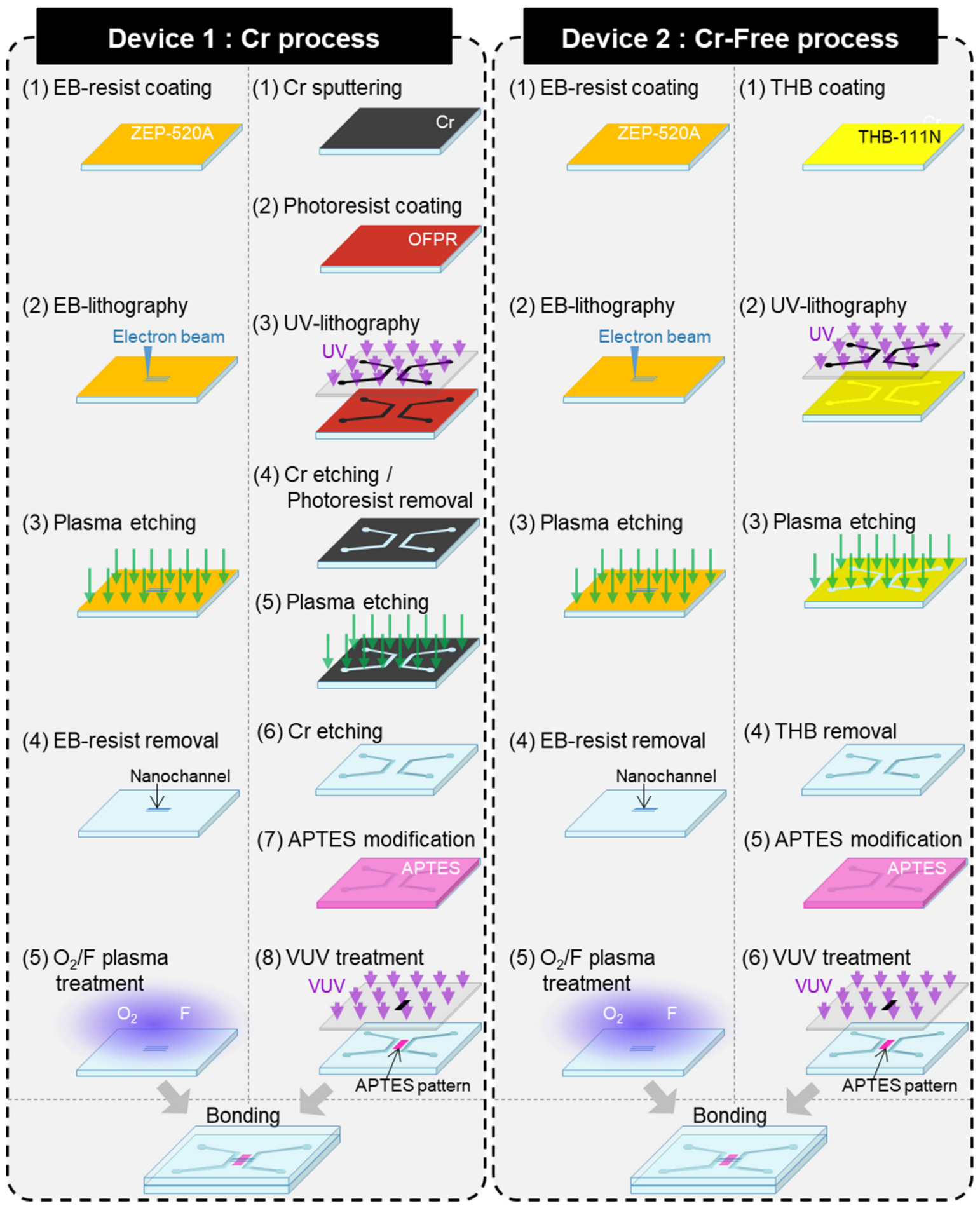

Figure 1. Processes for fabrication of nanofluidic devices using fused silica substrates. 
The obtained devices were used to evaluate the artifacts in chemical analysis. The setup is shown in Figure 2A. SureBlue TMB 1-Component (KPL, Gaithersburg, MD, USA), aqueous solution including $1.7 \mathrm{mM}$ TMB $\left(3,3^{\prime}, 5,5^{\prime}\right.$-tetramethylbenzidine), was introduced into extended nanochannels via microchannels and capillaries by pressure controllers. The fluidic control procedure is shown in Figure 2B). This operation was modeled after nanofluidic ELISA [30]. At first, TMB solution in the extended nanochannel was refreshed by applying $250 \mathrm{kPa}$ pressure. Then, flow was stopped at $0.5,1,2$, and $4 \mathrm{~min}$ for the incubation. At this time, uncolored TMB might be colored if oxidatively active contamination was present. After that, flow was started again. Signals associated with oxidized TMB (absorption max. wavelength at $655 \mathrm{~nm}$ [40]) were detected using a differential interference contrast thermal lens microscope (DIC-TLM; excitation: $660 \mathrm{~nm}$, probe: $532 \mathrm{~nm}$ ) [41]. The shape of the signals was expected to reflect the concentration distribution of oxidized TMB.

(A)

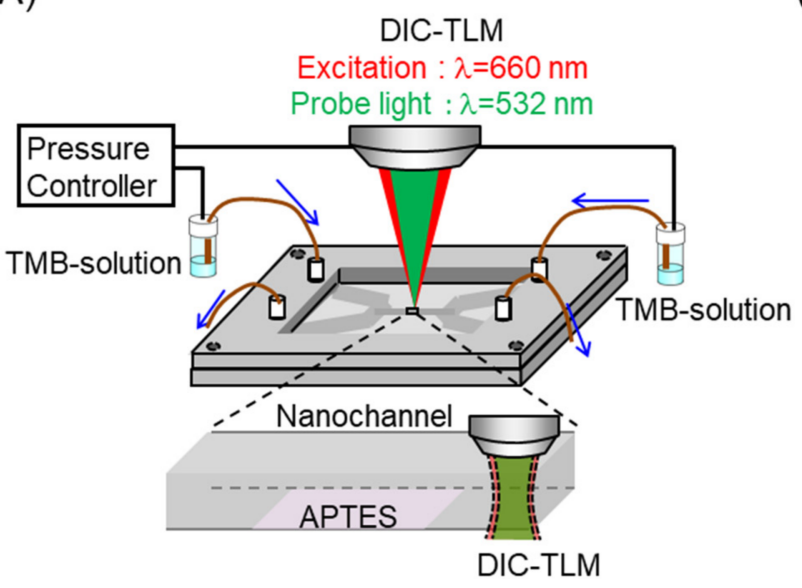

(B)

(1) Refreshing TMB solution in nanochannels

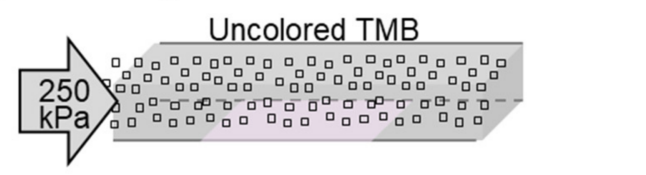

(2) Incubation under stopped flow

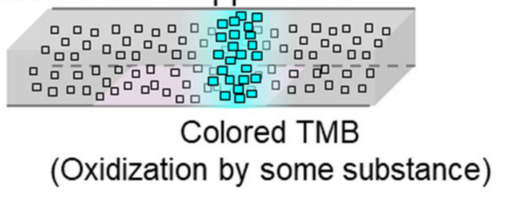

(3) Detection of colored TMB by DIC-TLM

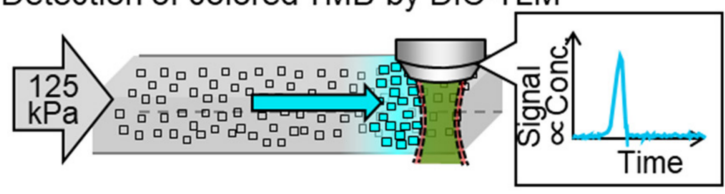

Figure 2. Evaluation of artifact on nanofluidic ELISA. (A) Setup. (B) Procedure of fluidic control.

\section{Results and Discussion}

Figure 3 show the results for the thickness of ZEP-520A after spin-coating twice. A thicker resist was obtained with a lower spin speed, with the maximum thickness being more than $2000 \mathrm{~nm}$. The etching selectivity of (fused silica)/(ZEP-520A) was approximately 0.5 ; therefore, channels deeper than $1000 \mathrm{~nm}$ could be produced by etching. The results of EB lithography and dry etching are shown in Figure 4. For the $1700 \mathrm{~nm}$-thick resist in Figure 4A, almost entirely $1000 \mathrm{~nm}$ scale channels could be fabricated for a $>0.4 \mu \mathrm{s}$ exposure. For the 1900 nm-thick resist in Figure 4B, channels wider than $2500 \mathrm{~nm}$ could be fabricated with $>0.4 \mu$ s exposure, although an exposure time of $>0.8 \mu$ s was required for 2000 nm-wide channels. No 1000-1500 nm channels were fabricated under these conditions. For the $2300 \mathrm{~nm}$-thick resist in Figure 4C, a longer exposure time (0.9-1.0 $\mu \mathrm{s})$ and wider exposure area (3000-4000 $\mathrm{nm}$ width) were required for channel fabrication. These results are quite reasonable because a longer exposure time and wider exposure area are required to complete lithography in the depth direction with thicker resists. These are the first reported lithography conditions for EB resists more than $1000 \mathrm{~nm}$ thick. After etching, a depth of $910 \mathrm{~nm}$ was obtained with the $1700 \mathrm{~nm}$-thick resist, a $1080 \mathrm{~nm}$ depth with the $1900 \mathrm{~nm}$-thick resist, and a $1300 \mathrm{~nm}$ depth with the $2300 \mathrm{~nm}$-thick resist. Typical results are shown in Figure 5. Figure 5A shows that a channel with a width of $1800 \mathrm{~nm}$ and a depth of $910 \mathrm{~nm}$ was successfully fabricated, and channels wider than $1000 \mathrm{~nm}$ could be fabricated based on the lithography principle (easier formation of wider channels). In addition, a 
channel with a width of $4300 \mathrm{~nm}$ and a depth of $1080 \mathrm{~nm}$, and a channel with a width of $4800 \mathrm{~nm}$ and a depth of $1300 \mathrm{~nm}$, were successfully fabricated, as shown in Figure 5B,C, and channels wider than $3000 \mathrm{~nm}$ could be fabricated under this channel depth condition. Fabrication of extended nanochannels whose width and depth are $1000 \mathrm{~nm}$ scale on a fused silica substrate is difficult by conventional methods [42]. For example, using mechanical methods such as blasting and milling, it is difficult to fabricate $1000 \mathrm{~nm}$ scale channels due to their resolution. In addition, optical methods and electrical methods are difficult to use to fabricate size- and shape-regulated extended nanochannels. Using the basic methods by lithography and etching, metal masks are necessary to fabricate $1000 \mathrm{~nm}$ scale channels. Therefore, $1000 \mathrm{~nm}$ scale channels were successfully fabricated on fused silica substrates without the use of chromium masks for the first time.

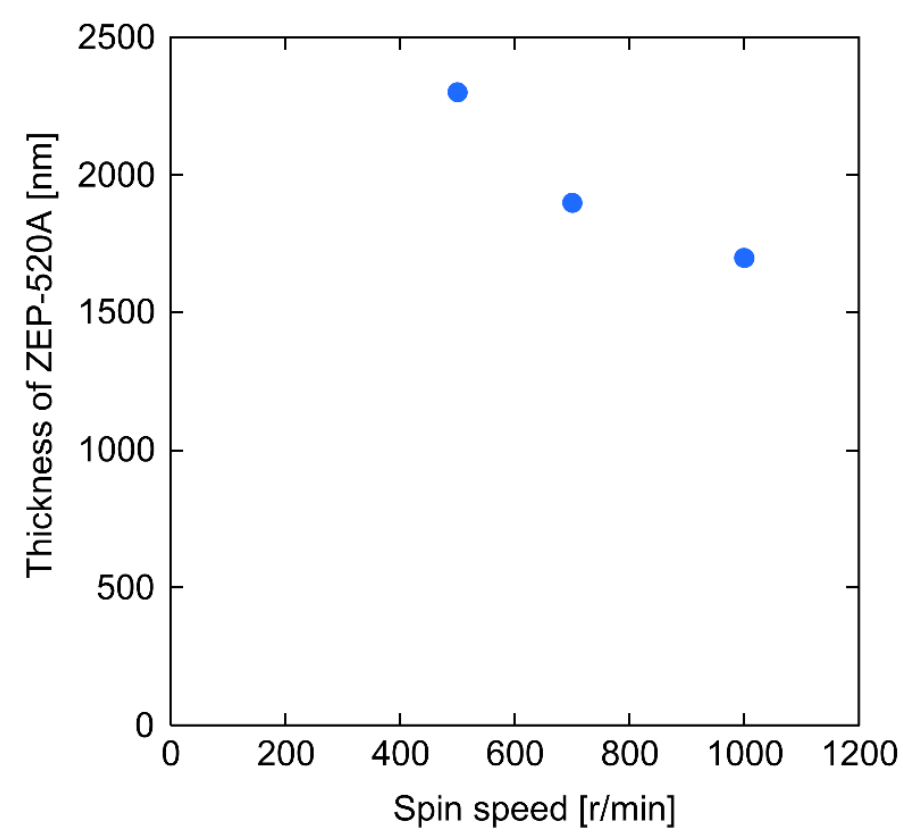

Figure 3. Thickness of spin-coated ZEP-520A with double coating.

(A)

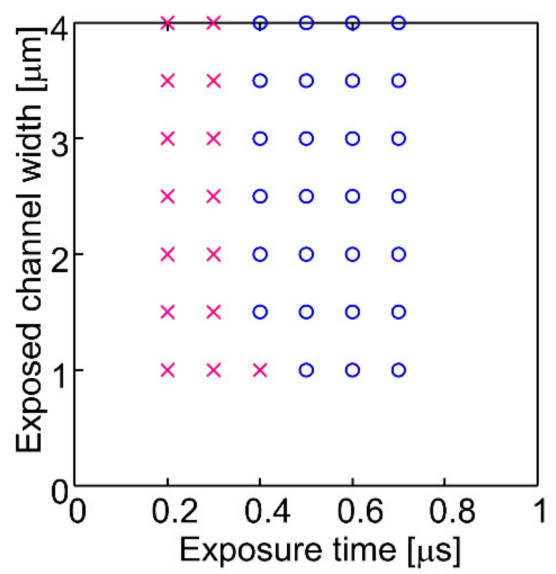

(B)

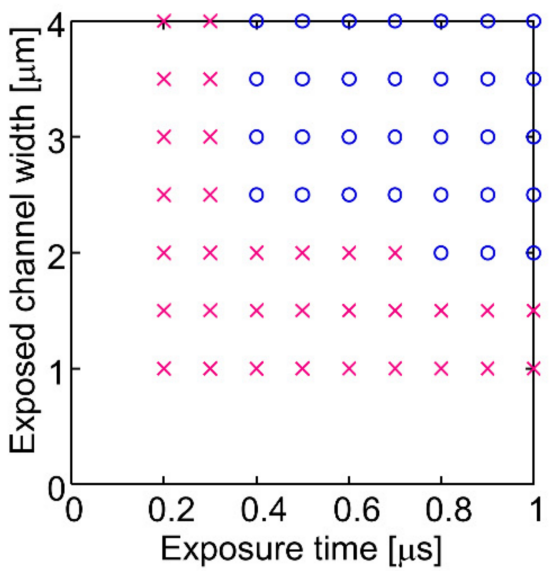

(C)

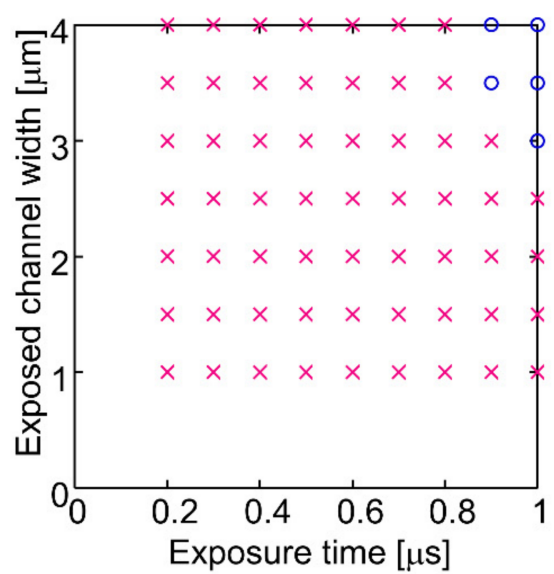

Figure 4. Relationship between exposure time and exposed channel width. Circles indicate conditions for successful channel fabrication, cross marks indicate conditions for failed channel fabrication. ZEP-520A EB resist with thicknesses of (A) $1700 \mathrm{~nm}$, (B) $1900 \mathrm{~nm}$, and (C) $2300 \mathrm{~nm}$. 

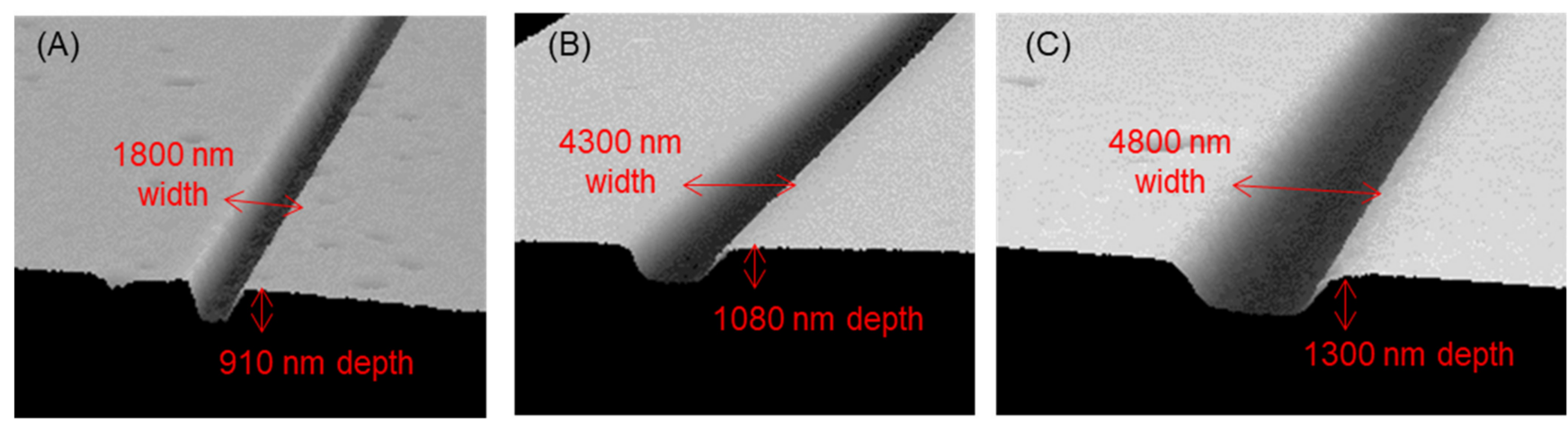

Figure 5. 3D profiles of fabricated extended nanochannels scanned by an optical profiler (WYKO NT9100A). Results for fabrication with (A) $1700 \mathrm{~nm}$ resist thickness, $1000 \mathrm{~nm}$ exposed channel width, and $0.5 \mu$ s exposure; (B) $1900 \mathrm{~nm}$ resist thickness, $2500 \mathrm{~nm}$ exposed channel width, and $0.4 \mu$ s exposure; and (C) $2300 \mathrm{~nm}$ resist thickness, $3000 \mathrm{~nm}$ exposed channel width, and $1.0 \mu$ s exposure.

Figure 6 shows DIC-TLM signals for TMB solutions in devices 1 and 2. The sizes of extended nanochannels of devices 1 and 2 were $2400 \mathrm{~nm}$ width and $800 \mathrm{~nm}$ depth, which showed successful fabrication by $1700 \mathrm{~nm}$-thick resist with two coatings at $1000 \mathrm{r} / \mathrm{min}$ in Figure 3, and by exposure of $2000 \mathrm{~nm}$ area with $0.6 \mu \mathrm{s} /$ dot in Figure 4A. As shown in Figure $6 \mathrm{~A}$, signals were obtained that indicated the oxidation of TMB, and the progress of the reaction is indicated by the increase in the signal intensity with increasing incubation time. ZEP-520A, OFPR, APTES and PEG (and of course $\mathrm{SiO}_{2}$ ) do not readily react with TMB. Therefore, chromium is the only candidate for reaction with TMB. Figure $6 \mathrm{~B}$ shows the DICTLM signals for TMB solutions in device 2. Device 2, which was fabricated using metal-free processes, was free from artifacts. The results presented here indicate that the presence of chromium in channels can induce artifacts, whereas such artifacts can be removed through the use of metal-free fabrication processes. In previous reports on ELISA in microchannels fabricated using a chromium mask on fused silica substrates [43-45], the artifacts induced by chromium were not discussed. It was suggested that effects of remnants of chromium on the microchannel surface were not significant due to lower surface-to-volume ratio compared to that of the extended nanochannel. Therefore, the artifacts induced by remnants of chromium are considered to be significant only in extended nanochannels. However, without metal-free fabrication processes developed in this study, the artifacts induced by remnants of chromium were difficult to verify. Therefore, this is the first finding that chromium remaining on the extended nanochannel surfaces during fabrication induced artifacts during the analysis. X-ray photoelectron spectroscopy (XPS) measurements were performed to evaluate the material composition on the fabricated substrates, and the results are shown in Figure 7. Around $580 \mathrm{eV}$, clear peaks were found for the substrate of device 1, but these were absent for a bare fused silica substrate. Based on the NIST XPS database [46], $\mathrm{Cr} 2 \mathrm{p}$ in $\mathrm{CrO}_{3}$ is observed at $579 \mathrm{eV}$; therefore, the results indicated that $\mathrm{Cr}^{6+}$ remained on the channel surfaces, reacted with THB, and induced artifacts.

The amount of reacted $\mathrm{Cr}^{6+}$ was estimated to elucidate the $\mathrm{Cr}^{6+}$ effect. Calibration of the DIC-TLM signals indicated that the reaction rate of TMB in the extended nanochannel was $3.6 \mu \mathrm{M} / \mathrm{min}$. For comparison, the TMB reaction rate was measured using a $20 \mu \mathrm{M}$ $\mathrm{K}_{2} \mathrm{CrO}_{7}$ solution, for which the rate was $0.33 \mu \mathrm{M} / \mathrm{min}$. We have previously reported that the reaction rate in nanochannels can be increased by $10^{1}$ times due to size confinement effects [27]. Therefore, whether or not to consider the size confinement effects would require at least a micromolar order (apparent concentration by nanochannel surface-to-volume ratio) reaction of $\mathrm{Cr}^{6+}$, which would have a significant effect on the chemical process. This is the first finding that chromium remaining on the channel surfaces during fabrication induced artifacts during the analysis, and the effect was significant. This finding will be valuable in designing nanofluidic devices and experiments. 
(A)

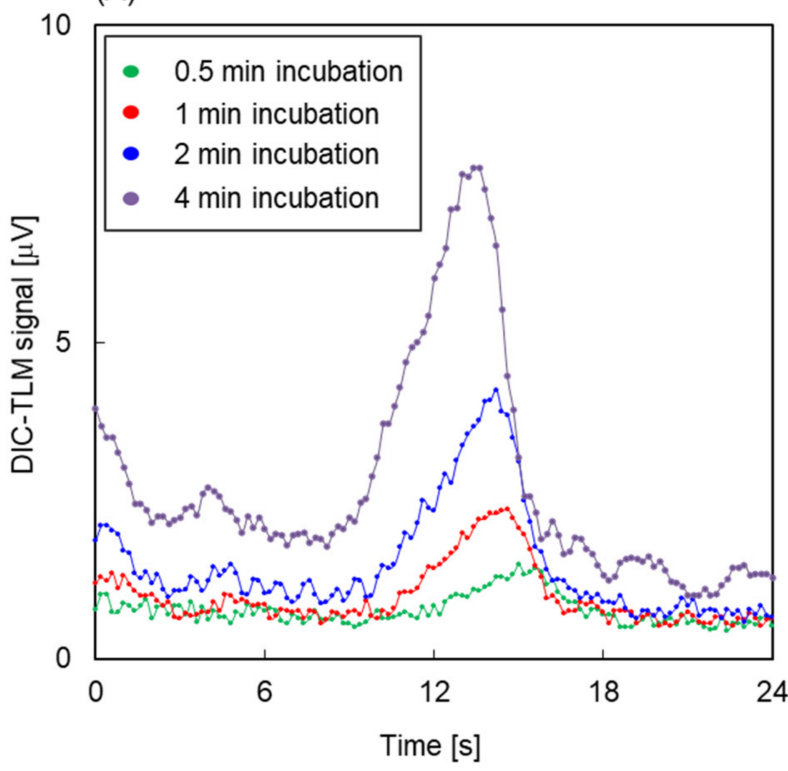

(B)

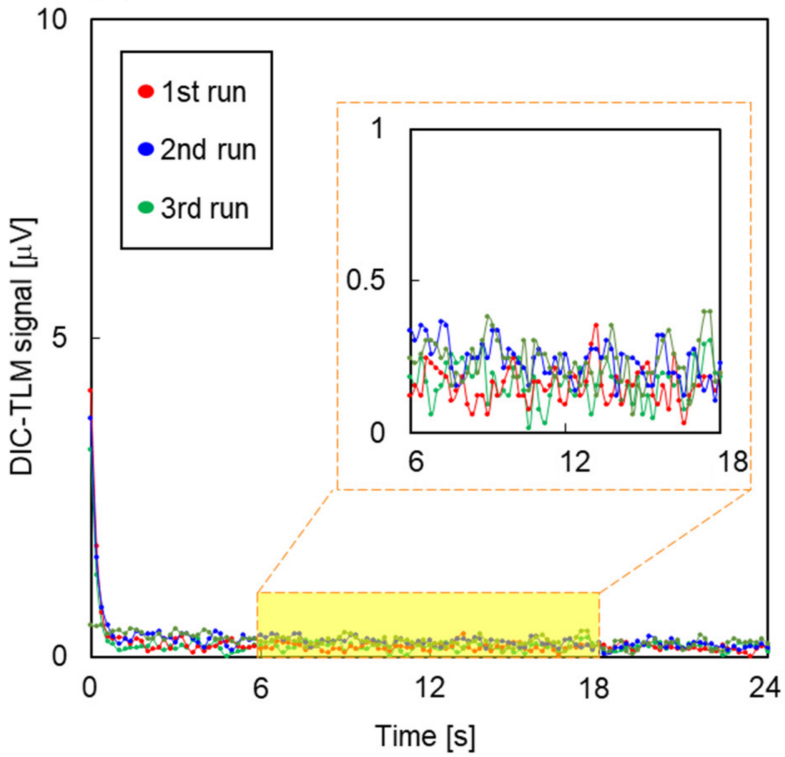

Figure 6. (A) DIC-TLM signals during $24 \mathrm{~s}$ flow with different incubation times for device 1. (B) DIC-TLM signals during $24 \mathrm{~s}$ flow in the 3 times experiments.

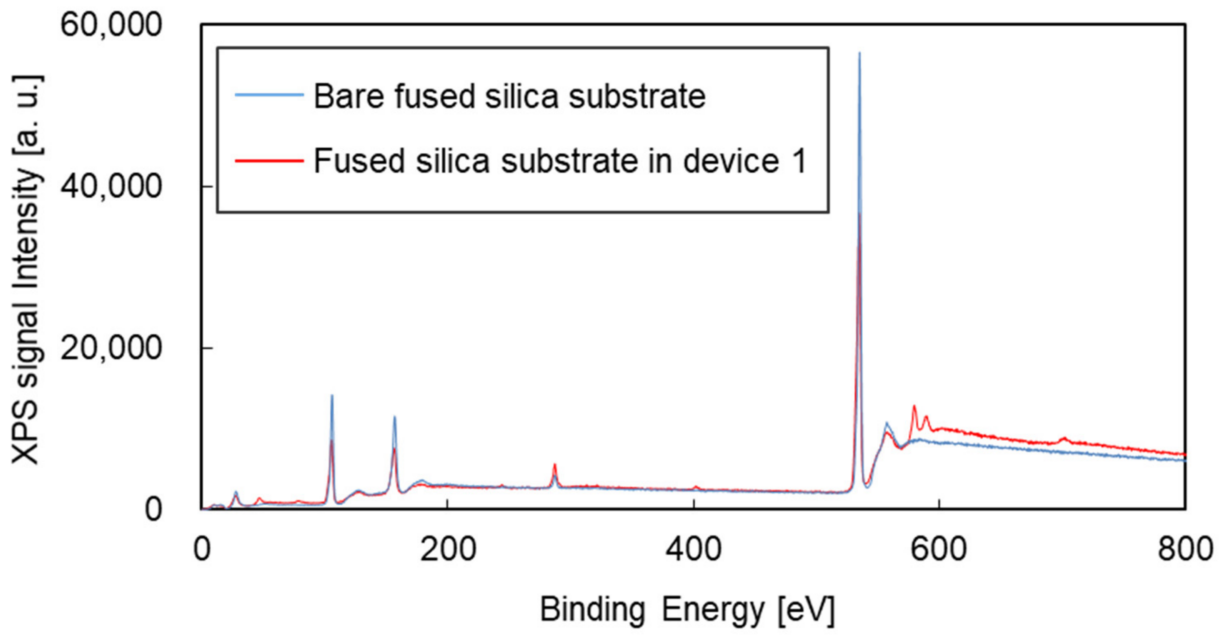

Figure 7. XPS signals for fused silica substrates before and after channel fabrication.

\section{Conclusions}

In this study, we presented processes for the fabrication of $1000 \mathrm{~nm}$ scale channels on fused silica substrates without using a metal mask. With control of the spin-coating speed, an EB resist was coated on the substrates with thicknesses in the range of $1700-2300 \mathrm{~nm}$. The EB exposure conditions for such thick resists were then optimized. As a result, channels with $1000 \mathrm{~nm}$ scale widths and depths were fabricated on fused silica substrates without the need for a metal mask. This is the first fabrication of $1000 \mathrm{~nm}$ scale channels without using a metal mask. DIC-TLM signals due to oxidized TMB were obtained for a nanofluidic device fabricated using a chromium mask. Chromium remaining on the channel surfaces during fabrication induced artifacts during the analysis, and the effect was significant at micromolar levels. This is the first finding that chromium remaining on the channel surfaces during fabrication induced artifacts during the analysis. The results of this study are expected to be valuable for the design of nanofluidic devices and experiments. In addition, metal-free micro/nanochannel fabrication processes can be realized to remove artifacts due to metal contamination, which will serve to advance the fundamental technologies employed in microfluidics and nanofluidics. 
Author Contributions: Conceptualization, K.M. (Kyojiro Morikawa) and T.K.; methodology, K.M. (Kyojiro Morikawa) and K.M. (Kazuma Mawatari); investigation, K.M. (Kyojiro Morikawa) and R.O.; writing, K.M. (Kyojiro Morikawa); supervision, K.M. (Kazuma Mawatari) and T.K. All authors have read and agreed to the published version of the manuscript.

Funding: This study was partially funded by a Kakenhi Grant-in-Aid (No. JP19K15417) from the Japan Society for the Promotion of Science (JSPS), and partially by the Core Research for Evolutional Science and Technology (CREST) program of the Japan Science and Technology Agency (JST) (No. JPMJCR14G1).

Acknowledgments: Fabrication and characterization facilities were provided in part by the Academic Consortium for Nano and Micro Fabrication associated with the University of Tokyo, Tokyo Institute of Technology, Keio University and Waseda University, Japan.

Conflicts of Interest: The authors declare no conflict of interest.

\section{References}

1. Reyes, D.R.; Iossifidis, D.; Auroux, P.A.; Manz, A. Micro total analysis systems. 1. introduction, theory, and technology. Anal. Chem. 2002, 74, 2623-2636. [CrossRef]

2. Auroux, P.A.; Iossifidis, D.; Reyes, D.R.; Manz, A. Micro total analysis systems. 2. analytical standard operations and applications. Anal. Chem. 2002, 74, 2637-2652. [CrossRef]

3. Song, H.; Li, H.W.; Munson, M.S.; Ha, T.G.V.; Ismagilov, R.F. On-chip titration of an anticoagulant argatroban and determination of the clotting time within whole blood or plasma using a plug-based microfluidic system. Anal. Chem. 2006, 78, 4839-4849. [CrossRef] [PubMed]

4. Tsao, C.W.; DeVoe, D.L. Bonding of thermoplastic polymer microfluidics. Microfluid. Nanofluid. 2009, 6, 1-16. [CrossRef]

5. Zhou, J.; Ellis, A.V.; Voelcker, N.H. Recent developments in PDMS surface modification for microfluidic devices. Electrophoresis 2010, 31, 2-16. [CrossRef]

6. Chin, C.D.; Linder, V.; Sia, S.K. Commercialization of microfluidic point-of-care diagnostic devices. Lab. Chip 2012, 12, 2118-2134. [CrossRef] [PubMed]

7. Sackmann, E.K.; Fulton, A.L.; Beebe, D.J. The present and future role of microfluidics in biomedical research. Nature 2014, 507, 181-189. [CrossRef]

8. Vladisavljević, G.T. Recent advances in the production of controllable multiple emulsions using microfabricated devices. Particuology 2016, 24, 1-17. [CrossRef]

9. Bojang, A.A.; Wu, H.S. Design, fundamental principles of fabrication and applications of microreactors. Processes $2020,8,891$. [CrossRef]

10. Yetisen, A.K.; Akram, M.S.; Lowe, C.R. Paper-based microfluidic point-of-care diagnostic devices. Lab. Chip 2013, 13, $2210-2251$. [CrossRef]

11. Hu, J.; Wang, S.Q.; Wang, L.; Li, F.; Pingguan-Murphy, B.; Lu, T.J.; Xu, F. Advances in paper-based point-of-care diagnostics. Biosens. Bioelectron. 2014, 54, 585-597. [CrossRef] [PubMed]

12. Carrell, C.; Kava, A.; Nguyen, M.; Menger, R.; Munshi, Z.; Call, Z.; Nussbaum, M.; Henry, C. Beyond the lateral flow assay: A review of paper-based microfluidics. Microelectron. Eng. 2019, 206, 45-54. [CrossRef]

13. Shakeri, A.; Jarad, N.A.; Leung, A.; Soleymani, L.; Didar, T.F. Biofunctionalization of glass- and paper-based microfluidic devices: A review. Adv. Mater. Interfaces 2019, 6, 1-16. [CrossRef]

14. Tokeshi, M.; Kikutani, Y.; Hibara, A.; Sato, K.; Hisamoto, H.; Kitamori, T. Chemical processing on microchips for analysis, synthesis, and bioassay. Electrophoresis 2003, 24, 3583-3594. [CrossRef]

15. Ohira, S.I.; Toda, K. Micro gas analyzers for environmental and medical applications. Anal. Chim. Acta 2008, 619, 143-156. [CrossRef]

16. Mijatovic, D.; Eijkel, J.C.T.; Van Den Berg, A. Technologies for nanofluidic systems: Top-down vs. bottom-up-A review. Lab. Chip 2005, 5, 492-500. [CrossRef]

17. Bocquet, L.; Charlaix, E. Nanofluidics, from bulk to interfaces. Chem. Soc. Rev. 2010, 39, 1073-1095. [CrossRef] [PubMed]

18. Napoli, M.; Eijkel, J.C.T.; Pennathur, S. Nanofluidic technology for biomolecule applications: A critical review. Lab. Chip 2010, 10, 957-985. [CrossRef]

19. Mawatari, K.; Kazoe, Y.; Shimizu, H.; Pihosh, Y.; Kitamori, T. Extended-nanofluidics: Fundamental technologies, unique liquid properties, and application in chemical and bio analysis methods and devices. Anal. Chem. 2014, 86, 4068-4077. [CrossRef]

20. Le, T.H.H.; Shimizu, H.; Morikawa, K. Advances in label-free detections for nanofluidic analytical devices. Micromachines 2020, 11, 885. [CrossRef]

21. Karnik, R.; Castelino, K.; Fan, R.; Yang, P.; Majumdar, A. Effects of biological reactions and modifications on conductance of nanofluidic channels. Nano Lett. 2005, 5, 1638-1642. [CrossRef]

22. Schoch, R.B.; Cheow, L.F.; Han, J. Electrical detection of fast reaction kinetics in nanochannels with an induced flow. Nano Lett. 2007, 7, 3895-3900. [CrossRef] 
23. Liao, T.; Li, X.; Tong, Q.; Zou, K.; Zhang, H.; Tang, L.; Sun, Z.; Zhang, G.J. Ultrasensitive Detection of MicroRNAs with Morpholino-functionalized nanochannel biosensor. Anal. Chem. 2017, 89, 5511-5518. [CrossRef]

24. Duan, C.; Alibakhshi, M.A.; Kim, D.K.; Brown, C.M.; Craik, C.S.; Majumdar, A. Label-Free electrical detection of enzymatic reactions in Nanochannels. ACS Nano 2016, 10, 7476-7484. [CrossRef]

25. Zevenbergen, M.A.G.; Singh, P.S.; Goluch, E.D.; Wolfrum, B.L.; Lemay, S.G. Stochastic sensing of single molecules in a nanofluidic electrochemical device. Nano Lett. 2011, 11, 2881-2886. [CrossRef]

26. Rassaei, L.; Mathwig, K.; Kang, S.; Heering, H.A.; Lemay, S.G. Integrated biodetection in a nanofluidic device. ACS Nano 2014, 8, 8278-8284. [CrossRef]

27. Yamamoto, K.; Morikawa, K.; Imanaka, H.; Imamura, K.; Kitamori, T. Picoliter enzyme reactor on a nanofluidic device exceeding the bulk reaction rate. Analyst 2020, 145, 5801-5807. [CrossRef] [PubMed]

28. Shimizu, H.; Morikawa, K.; Liu, Y.; Smirnova, A.; Mawatari, K.; Kitamori, T. Femtoliter high-performance liquid chromatography using extended-nano channels. Analyst 2016, 141, 6068-6072. [CrossRef] [PubMed]

29. Tsuyama, Y.; Morikawa, K.; Mawatari, K. Integration of sequential analytical processes into sub-100 nm channels: Volumetric sampling, chromatographic separation, and label-free molecule detection. Nanoscale 2021, 13, 8855-8863. [CrossRef] [PubMed]

30. Shirai, K.; Mawatari, K.; Ohta, R.; Shimizu, H.; Kitamori, T. A single-molecule ELISA device utilizing nanofluidics. Analyst 2018, 143, 943-948. [CrossRef] [PubMed]

31. Tokeshi, M.; Minagawa, T.; Uchiyama, K.; Hibara, A.; Sato, K.; Hisamoto, H.; Kitamori, T. Continuous-flow chemical processing on a microchip by Combining microunit operations and a multiphase flow network tion of complicated chemical processing on a microchip. Anal. Chem. 2002, 74, 1565-1571. [CrossRef] [PubMed]

32. Nakao, T.; Kazoe, Y.; Mori, E.; Morikawa, K.; Fukasawa, T.; Yoshizaki, A.; Kitamori, T. Cytokine analysis on a countable number of molecules from living single cells on nanofluidic devices. Analyst 2019, 144, 7200-7208. [CrossRef]

33. Morikawa, K.; Kazoe, Y.; Takagi, Y.; Tsuyama, Y.; Pihosh, Y.; Tsukahara, T.; Kitamori, T. Advanced Top-Down fabrication for a fused silica nanofluidic device. Micromachines 2020, 11, 995. [CrossRef]

34. Morikawa, K.; Matsushita, K.; Tsukahara, T. Rapid plasma etching for fabricating fused silica microchannels. Anal. Sci. 2017, 33, 1453-1456. [CrossRef]

35. ZEON Corporation Technical Report ZEP520A. Available online: https://www.nanophys.kth.se/nanolab/resists/zep520a-7-2 pdf (accessed on 18 June 2021).

36. Roy, S.; Gao, Z. Nanostructure-based electrical biosensors. Nano Today 2009, 4, 318-334. [CrossRef]

37. Fine, D.; Grattoni, A.; Goodall, R.; Bansal, S.S.; Chiappini, C.; Hosali, S.; Van De Ven, A.L.; Srinivasan, S.; Liu, X.; Godin, B.; et al. Silicon micro- and nanofabrication for medicine. Adv. Healthc. Mater. 2013, 2, 632-666. [CrossRef]

38. JSR Negative Tone THB Photoresists. Available online: https:/ /www.jsrmicro.com/electronic-materials/packaging-materials/ jsr-negative-tone-thb-photoresists (accessed on 20 July 2021).

39. Ohta, R.; Mawatari, K.; Takeuchi, T.; Morikawa, K.; Kitamori, T. Detachable glass micro/nanofluidic device. Biomicrofluidics 2019, 13, 024104. [CrossRef]

40. Holland, V.R.; Saunders, B.C.; Rose, F.L.; Walpole, A.L. A safer substitute for benzidine in the detection of blood. Tetrahedron 1974, 30, 3299-3302. [CrossRef]

41. Shimizu, H.; Mawatari, K.; Kitamori, T. Sensitive determination of concentration of nonfluorescent species in an extended-nano channel by differential interference contrast thermal lens microscope. Anal. Chem. 2010, 82, 7479-7484. [CrossRef]

42. Tang, T.; Yuan, Y.; Yalikun, Y.; Hosokawa, Y.; Li, M.; Tanaka, Y. Glass based micro total analysis systems: Materials, fabrication methods, and applications. Sens. Actuators B Chem. 2021, 339, 129859. [CrossRef]

43. Ohashi, T.; Mawatari, K.; Sato, K.; Tokeshi, M.; Kitamori, T. A micro-ELISA system for the rapid and sensitive measurement of total and specific immunoglobulin e and clinical application to allergy diagnosis. Lab. Chip 2009, 9, 991-995. [CrossRef] [PubMed]

44. Yanagisawa, N.; Dutta, D. Enhancement in the sensitivity of microfluidic enzyme-linked immunosorbent assays through analyte preconcentration. Anal. Chem. 2012, 84, 7029-7036. [CrossRef] [PubMed]

45. Pena, J.; McAllister, S.J.; Dutta, D. A glass microchip device for conducting serological survey of West Nile viral antibodies. Biomed. Microdevices 2014, 16, 737-743. [CrossRef] [PubMed]

46. NIST X-ray Photoelectron Spectroscopy (XPS) Database. Available online: https://srdata.nist.gov/xps/Default.aspx (accessed on 24 June 2021). 